\title{
Social suppression of ovarian cyclicity in captive and wild colonies of naked mole-rats, Heterocephalus glaber
}

\author{
C. G. Faulkes, D. H. Abbott and J. U. M. Jarvis* \\ MRC/AFRC Comparative Physiology Research Group, Institute of Zoology, Regent's Park, \\ London NWI 4RY,UK; and ${ }^{*}$ Department of Zoology, University of Cape Town, Rondebosch 7700 , \\ Republic of South Africa
}

\begin{abstract}
Summary. To investigate the endocrine cause of reproductive suppression in nonbreeding female naked mole-rats, animals from 35 colonies were studied in captivity. Urinary and plasma progesterone concentrations were elevated in pregnant females (urine: $10 \cdot 0-148 \cdot 4 \mathrm{ng} / \mathrm{mg} \mathrm{Cr}, 27$ samples from 8 females; plasma: $3 \cdot 6-30 \cdot 0 \mathrm{ng} / \mathrm{ml}, 5$ samples from 5 females; Days 21-40 of pregnancy) and cyclic breeding females (urine: $0.5-97.8 \mathrm{ng} / \mathrm{mg} \mathrm{Cr}, 146$ samples from 7 females; plasma: $<1.0-35.4 \mathrm{ng} / \mathrm{ml}, 25$ samples from 7 females). The latter group showed cyclic patterns of urinary progesterone, indicating a mean ovarian cycle length of $34.4 \pm 1.6$ days (mean \pm s.e.m.) with a follicular phase of $6.0 \pm 0.6$ days and a luteal phase of $27.5 \pm 1.3$ days ( 19 cycles from 9 breeding females). In non-breeding females urinary and plasma progesterone values were undetectable (urine: $<0.5 \mathrm{ng} / \mathrm{mg} \mathrm{Cr}, 232$ samples from 64 females; plasma: $<1.0 \mathrm{ng} / \mathrm{ml}, 7$ samples from 6 females $)$. Breeding females had higher $(P<0.001)$ plasma $\mathrm{LH}$ concentrations $(3.0 \pm 0.2 \mathrm{mi} . \mathrm{u} . / \mathrm{ml}, 73$ samples from 24 females $)$ than did non-breeding females $(1 \cdot 6 \pm 0 \cdot 1 \mathrm{mi} . \mathrm{u} . / \mathrm{ml}, 57$ samples from 44 females $)$. Urinary and plasma progesterone concentrations in non-breeding females from wild colonies situated near Mtito Andei, Kenya, were either below the assay sensitivity limit (urine: $<0.5 \mathrm{ng} / \mathrm{mg} \mathrm{Cr}, 11$ females from 2 colonies; plasma: $<1.0 \mathrm{ng} / \mathrm{ml}, 25$ females from 4 colonies), or very low (plasma: $1.6 \pm 0.6 \mathrm{ng} / \mathrm{ml}, 15$ females from 4 colonies).

In captivity, non-breeding females removed from their colonies (i.e. the dominant breeding female) and either paired directly with a non-breeding male $(\mathrm{N}=2)$, or removed and housed singly for 6 weeks before pairing with a non-breeding male $(N=5)$ may develop a perforate vagina for the first time in as little as 7 days. Urinary progesterone concentrations rose above $2 \cdot 0 \mathrm{ng} / \mathrm{mg} \mathrm{Cr}$ (indicative of a luteal phase) for the first time $8.0 \pm 1.9$ days after being separated.

These results suggest that ovulation is suppressed in subordinate non-breeding female naked mole-rats in captive and wild colonies, and show that plasma LH concentrations are significantly lower in these non-breeding females. This reproductive block in nonbreeding females is readily reversible if the social factors suppressing reproduction are removed.
\end{abstract}

Keywords: reproductive suppression; naked mole-rats; ovarian cycles; hystricomorph rodent

\section{Introduction}

Naked mole-rats are highly social hystricomorph rodents belonging to the family Bathyergidae, and are found in the semi-arid regions of East Africa. Living entirely underground, their burrows are extensive and can total 3-4 km in length (Brett, 1986). These mainly consist of foraging tunnels excavated in the search for underground roots and tubers which form the staple diet of the naked 
mole-rat. Colonies commonly contain 49-90 individuals but on occasion numbers have been reported to exceed 295 (Brett, 1986). Animals vary in mean body mass from $17 \cdot 7$ to $35.4 \mathrm{~g}$ according to their geographical location (Jarvis, 1985). Reproduction is monopolized by a single dominant female, 'the queen', and 1-3 large males within wild (Jarvis, 1985; Brett, 1986) and captive (Jarvis, 1978, 1981, 1990b; Lacey \& Sherman, 1990) colonies. The remaining mole-rats in a colony usually show no signs of sexual behaviour, do not become pregnant and are classed as non-reproductive (Jarvis, 1981). In addition to this extreme suppression of reproduction, a behavioural division of labour also exists amongst the non-reproductive animals, with smaller colony members performing higher frequencies of co-operative 'worker' type behaviours such as tunnel digging and foraging. As animals become larger they perform this type of behaviour less frequently and adopt a defensive role within the colony (Jarvis, 1981; Brett, 1986; Lacey \& Sherman, 1990; Faulkes et al., 1990a; Jarvis et al., 1990).

Examples of reproductive suppression are found over a wide range of mammalian species and generally these fall into two categories. In many rodents suppression results from increasing population densities and is mediated by urinary chemosignals, or primer pheromones (see Brown \& MacDonald, 1984). Suppression also occurs in hierarchical social groups of animals where a dominant individual may induce stress in subordinates as a result of agonistic behavioural interactions. The physiological consequences of this stress then lead to impaired or inhibited fertility (Wasser \& Barash, 1983; Kaplan et al., 1986; Abbott, 1987, 1988; Abbott et al., 1988).

Reproductive suppression in females may be manifested in a number of ways, including (i) puberty delay, e.g. the mouse, Mus musculus (van der Lee \& Boot, 1955; Massey \& Vandenbergh, 1980), and the prairie deer mouse, Peromyscus maniculatus bairdii (Kirkland \& Bradley, 1986); (ii) suppression of oestrus, e.g. mice (McClintock, 1983) and wild hopping mice, Notomys alexis (Breed, 1976); (iii) suppression of ovulation, e.g. the marmoset monkey, Callithrix jacchus (Abbott et al., 1988), and (iv) a block to embryo implantation, e.g. the white-footed mouse, Peromyscus leucopus (Haigh et al., 1988).

In a study of this phenomenon in female naked mole-rats (Faulkes et al., 1989), urinary progesterone concentrations were used as a marker of ovarian cyclicity in one breeding female, and have been shown to be continuously elevated in 8 pregnant females. In non-breeding females, values were undetectable, suggesting that ovulation was not occurring in suppressed individuals. The aims of the present study were to: (i) characterize the ovarian cycle of the naked mole-rat by measurement of urinary progesterone; (ii) to investigate in more detail the physiological nature of the block to reproduction in non-breeding subordinate females in captive and wild colonies of naked mole-rats; (iii) investigate anterior pituitary function in breeding and non-breeding females by measurement of circulating bioactive LH concentrations, and (iv) elucidate the rapidity with which ovarian cycles commence when non-breeding females are removed from their colonies and become reproductively active.

\section{Materials and Methods}

\section{Animals and sampling}

Captive colonies of naked mole-rats were maintained at the Institute of Zoology, London, and at the University of Cape Town, South Africa, using artificial burrow systems (see Brett, 1985), in rooms heated to $28-30^{\circ} \mathrm{C}$ and with relative humidity of $40-60 \%$. The burrow systems consisted of a series of interconnecting Perspex tubes with a nest chamber, a toilet chamber, and a chamber where food was introduced. The nest chambers were heated to $32-34^{\circ} \mathrm{C}$ with a thermostatically controlled heat lamp to provide additional heating in London colonies. In Cape Town $40 \mathrm{~W}$ lamps were positioned at several points of the colony. The total tunnel length varied from 2 to $15 \mathrm{~m}$, according to the number of animals in the colony, which ranged from pairs up to 72 individuals. Fresh food was given daily ad libitum and included sweet corn, sweet potatoes, carrot, potato, apple, and banana. A cereal supplement containing vitamins and minerals was also provided once per week (London colonies) or daily (Cape Town colonies). Animals were numbered and identified by a system of toe clipping and tattoos. Individuals undergoing regular urine sampling were 
clearly numbered using a felt-tipped marker pen at approximately weekly intervals. Altogether, 35 captive colonies were used in this study.

Urine sampling in captive colonies. To investigate ovarian activity in breeding and non-breeding females, urine samples were collected over various periods between April 1987 and May 1989.

Urine was chosen for routine progesterone determination in preference to blood because it can be obtained by a non-invasive technique and disturbance to the animals was minimized, and because it was not possible to obtain blood samples with sufficient regularity to investigate ovarian cycles, due to the small size of the animals (average body weight in captive colonies: $35 \mathrm{~g}$ ). Urine is also widely used as a medium for hormonal analysis in other species and the analytical methods have been well validated (see Lasley, 1985; Hodges, 1986).

Urine sampling involved the removal of all the shavings from the toilet chamber in each colony and wiping the chamber clean with tissue paper. Immediately after each urination, the sample was collected in a glass pipette. Following collection of each sample, the toilet chamber was wiped clean with tissue paper. Samples were placed in a freezer within $1 \mathrm{~h}$ of collection, and stored at $-20^{\circ} \mathrm{C}$ until hormone determination. Sampling was carried out between 08:00 and 18:00 h.

Blood sampling in captive colonies. Animals were hand-held and blood was obtained by cutting the tip of the tail with a sterile scalpel blade. A volume of $300-400 \mu \mathrm{l}$ blood was collected by capillary action using heparinized microhaematocrit tubes. The wound was then treated with an antibiotic powder (Aureomycin), and the animal returned to its colony. After collection the samples were stored on ice before being centrifuged, and the plasma was stored at $-20^{\circ} \mathrm{C}$ before hormone determination.

Collection of blood and urine samples from wild colonies. Naked mole-rats from 4 wild colonies were captured near Mtito Andei, Kenya, approximately $230 \mathrm{~km}$ south east of Nairobi (for details of capture technique see Faulkes $\mathrm{et} \mathrm{al}$., 1990b; Jarvis, 1990b). Blood was withdrawn into heparinized syringes by cardiac puncture after the animal had been decapitated, and was immediately placed on ice for $4-7 \mathrm{~h}$. Plasma was then separated by centrifugation, frozen immediately and stored between -5 and $-20^{\circ} \mathrm{C}$ until hormone assay. Urine was withdrawn from the bladder using a hypodermic needle and syringe, then immediately placed on ice for $4-7 \mathrm{~h}$ until freezing and storage between -5 and $-20^{\circ} \mathrm{C}$, before assay. No breeding queens, which are identified by their large body size, well developed teats and prominent external genitalia, were captured. Samples from wild-caught animals were therefore restricted to non-breeding females.

\section{Hormone determinations}

Radioimmunoassay of progesterone. Before progesterone assay all urine samples were subjected to a determination of creatinine as described by Bonney et al. (1982). All urinary progesterone concentrations were expressed as mass per $\mathrm{mg}$ creatinine $(\mathrm{mg} / \mathrm{Cr})$ to correct for dilution of urine.

Progesterone concentrations were determined in petroleum ether-extracted urine $(50-100 \mu l)$ and plasma samples ( $20-40 \mu \mathrm{l}$ ) by radioimmunoassay without chromatography (Hodges et al., 1983), using WHOCHW 1B anti-progesterone antibody. The sensitivity limit of the assay (determined as $90 \%$ binding) was $10 \mathrm{pg} /$ tube. Intra- and inter-assay precision, expressed as the coefficient of variation for repeated determinations of a quality control, was $6.0 \%(n=11)$ and $7 \cdot 1 \%$ $(n=19)$ respectively.

Dilutions of urine from pregnant queens containing high levels of progesterone were parallel to the reference preparation (Sigma, PO130, 4-pregnene-3,20-dione) over the range 6.2-400 pg/tube. The mean \pm s.e.m. recovery of unlabelled progesterone added to a naked mole-rat urine pool was $97 \cdot 1 \pm 3 \cdot 5(n=7)$ over the standard curve range of $6 \cdot 2-400 \mathrm{pg} /$ tube.

Chromatographic separation of progesterone from the samples using Celite columns (Hodges et al., 1981) was not required because there was no significant difference between urinary progesterone determinations made with or without chromatography. Regression analysis of the progesterone values with and without chromatography gave the equation $y=0.89 x+1.76$, and a slope and intercept not significantly different from 1 and 0 respectively. The regression coefficient $r$, was 0.95 . Therefore there were no identifiable non-specific factors interfering with progesterone determination by this method.

Luteinizing hormone bioassay. Luteinizing hormone (LH) was measured using an in-vitro bioassay based on the production of testosterone by dispersed mouse Leydig cells (Van Damme et al., 1974). Details of the method have been described previously (Harlow et al., 1984; Hodges et al., 1987). Only plasma samples were used and these were assayed in duplicate at two dilutions of $1: 20$ and $1: 40$ and compared with a rat $\mathrm{LH}$ standard (the rLH antigen preparation: $\mathrm{rLH}-1-7$ ) over the range $2-0.0625 \mathrm{mi} . \mathrm{u}$. $/ \mathrm{ml}$. The testosterone produced was measured by radioimmunoassay (see Hodges et al., 1987).

Dilutions of a naked mole-rat pituitary homogenate containing high amounts of $\mathrm{LH}$ were parallel to the reference preparation. The sensitivity limit of the assay (determined at $90 \%$ binding) was $0 \cdot 1 \mathrm{mi} . \mathrm{u} . / \mathrm{ml}$. Intra- and inter-assay coefficient of variations were $10 \%(n=15)$ and $16 \%(n=9)$ respectively.

Results from the plasma LH determinations were analysed statistically using Student's $t$ test. 


\section{Experimental procedures}

Ovarian activity in captive non-breeding females. A total of 232 urine samples were collected from 64 non-breeding females from 7 captive colonies over periods from January to March, 1986, and from April 1987 to May 1989. To establish whether or not these females were undergoing ovarian cycles, these samples were subjected to urinary progesterone determination. In addition, 7 plasma samples were collected from 6 females, and also assayed for progesterone.

Ovarian cyclicity in captive breeding females. A total of 121 urine samples were collected from 9 non-pregnant breeding females from July 1987 to May 1989, and 25 plasma samples were collected from 7 of the females. Two of these females were housed in colonies, while the other 7 were housed as male/female pairs and also used in the study of reproductive activation described below. Of the 9 females, 6 had either had previous pregnancies, or became pregnant during the course of the study.

Cycle lengths were calculated from urinary progesterone profiles plotted against time (days) as follows: Day 0 was designated as the day before a sustained rise in urinary progesterone above $2.0 \mathrm{ng} / \mathrm{mg} \mathrm{Cr}$, and was assumed to correspond approximately to the day of ovulation. Day 1 was designated as the start of the luteal phase of the cycle. The end of the luteal phase was designated as the day on which a rapid and sustained fall in urinary progesterone below $2.0 \mathrm{ng} / \mathrm{mg}$ $\mathrm{Cr}$ occurred. The follicular phase of the cycle was defined as the period between the end of the luteal phase of one cycle and Day 0 of the following luteal phase. The total cycle length was calculated as the period between the end of successive luteal phases.

Ovarian cyclicity in wild non-breeding females. Urine samples from 11 non-breeding females in 2 colonies and plasma samples from 40 non-breeding females in 4 colonies were collected during December 1987, and subjected to progesterone determination.

Plasma LH concentrations in captive breeding and non-breeding females. Plasma samples were taken from 44 nonbreeding females and 24 breeding queens over the period April 1987 to May 1989, from a total of 30 colonies. It was not possible to standardize the reproductive state of the queens from which the samples were taken. The plasma was assayed for bioactive $\mathrm{LH}$ concentrations.

Reproductive activation in captive non-breeding females. To study the latency from acyclicity to the start of ovarian cyclicity, non-breeding females were removed from their colony and paired with a male $(\mathrm{N}=2)$, or removed, housed singly for 6 weeks then paired with a male $(N=5)$. Urine samples were collected over periods up to 80 days before and 200 days after separation from their parent colony.

The females were examined at weekly intervals after separation to ascertain the time of vaginal perforation. Although no routine behavioural observations were carried out, casual observations of mating were noted.

\section{Results}

\section{Ovarian activity in captive non-breeding females}

Urinary progesterone concentrations were consistently below the sensitivity limit of the assay $(<0.5 \mathrm{ng} / \mathrm{mg} \mathrm{Cr} ; 232$ samples from 64 females in 7 colonies). These results are summarized in Table 1 and the absence of post-ovulatory progesterone confirms our preliminary findings (Faulkes et al., 1989) which suggested that non-breeding females failed to ovulate. Plasma progesterone concentrations were similarly below the sensitivity limit of the assay $(<1.0 \mathrm{ng} / \mathrm{ml}, 7$ samples from 6 females).

There were 2, isolated exceptions to the results shown in Table 1 among non-breeding females. In 2 further colonies, a non-breeding female in each exhibited urinary progesterone concentrations above $0.5 \mathrm{ng} / \mathrm{mg} \mathrm{Cr}$. In one, out of 9 samples collected over a 44-day period, 2 of these contained urinary progesterone at concentrations of 1.7 and $8.4 \mathrm{ng} / \mathrm{mg} \mathrm{Cr}$ respectively. In the other case, 3 samples were collected from a non-breeding female, one of which contained $4.4 \mathrm{ng} / \mathrm{mg} \mathrm{Cr}$ of progesterone. These appear to be isolated events and did not reflect any sustained ovarian activity.

\section{Ovarian cyclicity in captive breeding females}

Based on the assumption that the progesterone measured was ovarian in origin, non-pregnant breeding females showed cyclic patterns of urinary progesterone, indicating a mean ( \pm s.e.m.) ovarian cycle length of $34.4 \pm 1.6$ days with a follicular phase of $6.0 \pm 0.6$ days, and a luteal phase of $27 \cdot 5 \pm 1 \cdot 3$ days ( 19 cycles from 9 breeding females). These results were combined by synchronizing at 
Table 1. Mean \pm s.e.m. urinary progesterone concentrations $(\mathrm{ng} / \mathrm{mg} \mathrm{Cr})$ in 405 samples from 75 female naked mole-rats

\begin{tabular}{|c|c|c|c|c|}
\hline & \multicolumn{3}{|c|}{ Dominant breeding female } & \multirow{2}{*}{$\begin{array}{c}\text { Subordinate } \\
\text { non-breeding } \\
\text { females }\end{array}$} \\
\hline & $\begin{array}{l}\text { Follicular } \\
\text { phase }\end{array}$ & $\begin{array}{l}\text { Luteal } \\
\text { phase }\end{array}$ & Pregnant ${ }^{*}$ & \\
\hline \multicolumn{5}{|l|}{ Colony } \\
\hline B & - & - & - & $\begin{array}{c}<0.5 \\
N=80,1199\end{array}$ \\
\hline $\mathrm{D}$ & $\begin{aligned} & <0 \cdot 5 \\
\mathrm{~N}= & 3,3 \text { cycles }\end{aligned}$ & $\begin{array}{c}7 \cdot 9 \pm 2 \cdot 2 \\
\mathrm{~N}=6,2 \text { cycles }\end{array}$ & $\begin{array}{c}10 \cdot 0 \\
\mathrm{~N}=1,1 \text { preg. }\end{array}$ & $\begin{array}{c}<0.5 \\
\mathrm{~N}=20,6 \uparrow q\end{array}$ \\
\hline $\mathbf{N}$ & $\begin{aligned} & <0 \cdot 5 \\
\mathrm{~N}= & 2,2 \text { cycles }\end{aligned}$ & $\begin{array}{c}13 \cdot 0 \pm 4 \cdot 0 \\
\mathrm{~N}=8,2 \text { cycles }\end{array}$ & $\begin{array}{c}23 \cdot 2 \pm 7 \cdot 2 \\
\mathrm{~N}=3,1 \text { preg. }\end{array}$ & - \\
\hline 2200 & - & - & $\begin{array}{c}31 \cdot 0 \pm 6.8 \\
N=3,2 \text { preg. }\end{array}$ & $\begin{array}{c}<0.5 \\
N=32,9 \text { क्ष }\end{array}$ \\
\hline 300 & - & - & $\begin{array}{c}31 \cdot 3 \pm 4 \cdot 9 \\
\mathrm{~N}=5,1 \text { preg. }\end{array}$ & $\begin{array}{c}<0.5 \\
\mathrm{~N}=39,7 \wp q\end{array}$ \\
\hline 7 & - & - & $\begin{array}{c}64 \cdot 2 \pm 28 \cdot 9 \\
N=2,1 \text { preg. }\end{array}$ & $\begin{array}{c}<0.5 \\
\mathrm{~N}=19,4 q q\end{array}$ \\
\hline 400 & - & - & $\begin{array}{c}89 \cdot 4 \pm 20 \cdot 2 \\
\mathrm{~N}=5,1 \text { preg. }\end{array}$ & $\begin{array}{c}<0.5 \\
\mathrm{~N}=32,1999\end{array}$ \\
\hline 1100 & - & - & - & $\begin{aligned} & <0.5 \\
\mathbf{N}= & 10,8 \% q\end{aligned}$ \\
\hline \multicolumn{5}{|l|}{ Pairs } \\
\hline G & $\begin{array}{c}0.9 \pm 0.3 \\
\mathrm{~N}=4,4 \text { cycles }\end{array}$ & $\begin{array}{c}12 \cdot 3 \pm 2 \cdot 9 \\
\mathrm{~N}=15,4 \text { cycles }\end{array}$ & - & - \\
\hline $\mathbf{H}$ & $\begin{array}{c}<0.5 \\
\mathrm{~N}=8,4 \text { cycles }\end{array}$ & $\begin{array}{c}12 \cdot 1 \pm 1 \cdot 8 \\
\mathrm{~N}=29,4 \text { cycles }\end{array}$ & - & - \\
\hline K & $\begin{array}{c}0.7 \pm 0.2 \\
\mathrm{~N}=7,4 \text { cycles }\end{array}$ & $\begin{array}{c}9 \cdot 5 \pm 1 \cdot 2 \\
\mathrm{~N}=28,5 \text { cycles }\end{array}$ & - & - \\
\hline Q & $\begin{aligned} & <0.5 \\
N= & 6,2 \text { cycles }\end{aligned}$ & $\begin{array}{c}14 \cdot 6 \pm 5 \cdot 7 \\
\mathrm{~N}=7,1 \text { cycle }\end{array}$ & $\begin{array}{c}17 \cdot 2 \pm 6 \cdot 0 \\
N=4,1 \text { preg. }\end{array}$ & - \\
\hline $\mathbf{R}$ & $\begin{array}{c}<0.5 \\
\mathrm{~N}=7,3 \text { cycles }\end{array}$ & $\begin{array}{c}9 \cdot 1 \pm 1 \cdot 6 \\
N=16,2 \text { cycles }\end{array}$ & $\begin{array}{c}16 \cdot 1 \pm \quad 7 \cdot 2 \\
\mathrm{~N}=4,1 \text { preg. }\end{array}$ & - \\
\hline
\end{tabular}

*Samples were taken between Days 21 and 40 of the 72-day gestational period, when urinary progesterone concentrations are maximal (Faulkes et al., 1989a). The numbers of samples shown represent individual progesterone values taken from the indicated number of separate ovarian cycles or pregnancy (preg.).

Day 0 , and the mean \pm s.e.m. urinary progesterone profile over the entire cycle, assuming a mean cycle length of 34 days, is illustrated in Fig. 1. Mating occurred at a mean of $1.0 \pm 0.6$ days before Day 0 (range: 0 to -3 days; 6 observations from 4 females), corresponding to $\sim 1$ day before the proposed day of ovulation. Mating is not often observed in the naked mole-rat because oestrus is short (2-24 h; Jarvis, in 1990b).

Urinary progesterone remained low during the follicular phase ( $<2.0 \mathrm{ng} / \mathrm{mg} \mathrm{Cr}$ ), but was elevated during the luteal phase $(2.0-97.8 \mathrm{ng} / \mathrm{mg} \mathrm{Cr}, 146$ samples from 7 females), as shown for 7 of the 9 females in Table 1, together with values for Days 21-40 of pregnancy for comparison (Faulkes et al., 1989).

Plasma progesterone values demonstrated similar differences between follicular and luteal phases of the ovarian cycle and pregnancy (follicular: $1.02 \pm 0.02 \mathrm{ng} / \mathrm{ml}, 13$ samples from 7 females; luteal: $16.8 \pm 3.5 \mathrm{ng} / \mathrm{ml}, 12$ samples from 6 females; Days $21-40$ of pregnancy: $16.6 \pm 4.4 \mathrm{ng} / \mathrm{ml}$, 5 samples from 5 females). 


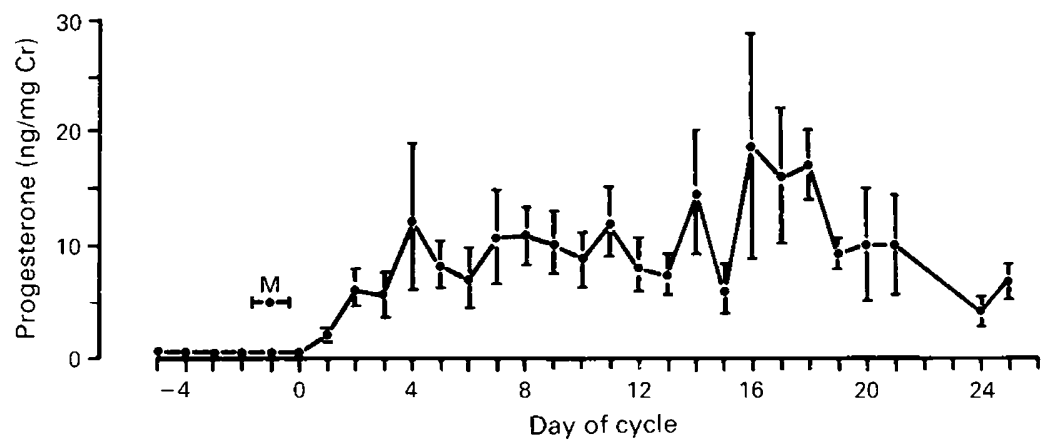

Fig. 1. Mean \pm s.e.m. urinary progesterone concentrations from 121 urine samples taken from a total of 19 cycles from 9 breeding females. Individual cycles were standardized at Day 0 , corresponding to the day preceding a sustained rise in urinary progesterone above $2.0 \mathrm{ng} / \mathrm{mg}$ $\mathrm{Cr}$, and combined to produce a composite urinary progesterone profile for the ovarian cycle of the naked mole-rat. Each point is the mean \pm s.e.m. of individual values obtained for a particular day $(\mathrm{N}=3-8)$. Insufficient samples were obtained for Days $22,23,26,27 \& 28$, and samples from Days 0 to -5 were all below the sensitivity limit of the assay $(<0.5 \mathrm{ng} / \mathrm{mg} \mathrm{Cr})$. $\mathrm{M}=$ mean \pm s.e.m. time of observed matings ( $n=6$ observations from 4 females).

\section{Ovarian cyclicity in wild non-breeding females}

Both urinary and plasma progesterone concentrations were either below the sensitivity limit of the assay (urine: $<0.5 \mathrm{ng} / \mathrm{mg} \mathrm{Cr}, 11$ females from 2 colonies; plasma: $<1.0 \mathrm{ng} / \mathrm{ml}, 25$ females from 4 colonies) or very low (plasma: $1.6 \pm 0.6 \mathrm{ng} / \mathrm{ml}, 15$ females from 4 colonies), indicating a lack of ovarian activity in these non-breeding females.

\section{Plasma LH concentrations in breeding and non-breeding females}

Breeding females had higher $(P<0.001)$ plasma LH concentrations $(3.0 \pm 0.2 \mathrm{mi} . \mathrm{u} . / \mathrm{ml}, 73$ samples from 24 females), than non-breeding females $(1.6 \pm 0.1 \mathrm{mi} . \mathrm{u} . / \mathrm{ml}, 57$ samples from 44 females), suggesting that the failure of ovulation in non-breeding females may reflect low pituitary LH secretion, or a more rapid clearance from the circulation.

\section{Reproductive activation in non-breeding females}

In this study non-breeding females removed from their colony and paired with a male $(\mathrm{N}=2)$, or removed and housed singly for 6 weeks before pairing with a male $(\mathrm{N}=5)$ began ovarian cyclicity. In the latter group urinary progesterone concentrations rose above $2.0 \mathrm{ng} / \mathrm{mg} \mathrm{Cr}$ (indicative of a luteal phase) for the first time $5 \cdot 8 \pm 1 \cdot 2$ days after being singly housed. In one of these individuals, Female 4 , the peak in urinary progesterone seen whilst the animal was singly housed did not appear to represent a complete luteal phase as its duration was only about 8 days (Fig. 2). However, normal ovarian cyclicity began after pairing with a male. This contrasts with female 29 which underwent a normal cycle whilst singly housed (Fig. 2) and was typical of the other 4 females. Two of these 5 females developed perforate vaginas for the first time within 21 days of separation, whilst singly housed. The vaginae of the remaining 3 females became perforate within 7,14 and 21 days of pairing with a male (for example see Females 4 and 29, Fig. 2). In the females paired directly with a male, urinary progesterone rose for the first time above $2 \cdot 0 \mathrm{ng} / \mathrm{mg} \mathrm{Cr} 9$ and 18 days after separation from their parent colonies. The vaginas of these females became perforate 14 and 7 days respectively, after separation from their colonies. The urinary progesterone profile for one of these individuals, Female 21, is illustrated in Fig. 2.

Three of the 5 singly housed females underwent one cycle immediately after pairing with the male, then became pregnant at the following oestrus. Progesterone profiles for 2 of these females 


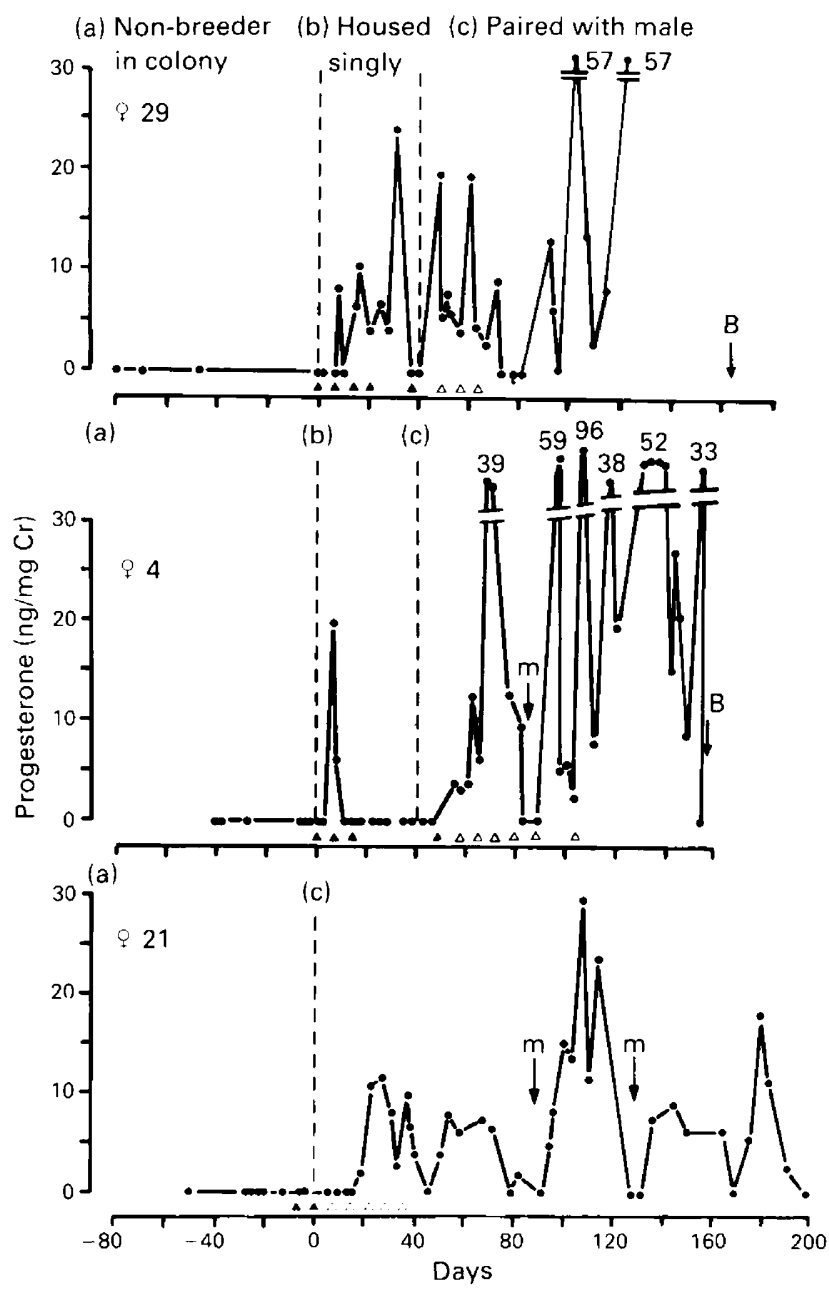

Fig. 2. Urinary progesterone profiles for 3 of the 7 non-breeding females removed from their colonies and paired with a male, or housed singly before pairing with a male. $\mathbf{M}=$ observations of mating; $\mathbf{B}=$ birth of litter; $\boldsymbol{\Delta}$ = vagina imperforate; $\Delta=$ vagina perforate.

Nos 4 and 29, are illustrated in Fig. 2. The elevated urinary progesterone from Day 89 in Female 4, and from Day 80 onwards in Female 29 represents pregnancy.

\section{Discussion}

The results of this study are consistent with our previous findings (Faulkes et al., 1989a) and show that in non-breeding female naked mole-rats, the socially-induced block to reproduction is due to a failure of these females to ovulate. We have also shown for the first time that this physiological state is also a characteristic of non-breeding females in wild populations of naked mole-rats. Histological examination of the reproductive tract of wild and captive females confirmed this hypothesis, because the ovaries of non-breeding females lacked both preovulatory follicles and corpora lutea, in contrast to those of breeding queens (C. G. Faulkes, unpublished data; Jarvis 1990a). The very low plasma LH concentrations measured in non-breeding females, in comparison to those in breeding 
females, provides circumstantial evidence that the failure of ovulation may be due to insufficient secretion of LH from the anterior pituitary. Although single plasma samples do not give information regarding pulse frequency and amplitude of LH secretion, the consistency of low LH levels found in non-breeding females suggested that either LH pulse frequency or amplitude, or both were reduced in these females. In the common marmoset monkey, suppressed pituitary LH secretion due to an inhibition of hypothalamic GnRH release has been shown to be the central mediating factor responsible for the suppression of ovulation in socially-induced infertility found in subordinate females (Abbott et al., 1988).

The ovarian cycle of the naked mole-rat with its long luteal phase of approximately 28 days is similar to that reported for other hystricomorph rodents. In guinea-pigs, the corpus luteum of an un-mated, non-pregnant female secretes progesterone for 15-17 days (Weir \& Rowlands, 1974), and cycle lengths of other hystricomorphs are comparable, e.g. the cuis, Galea musteloides (22 days), chinchilla, Chinchilla laniger (40 days), and acouchi, Myoprocta pratti (30-55 days) (Tam, 1974). The extended periods of elevated progesterone in hystricomorph rodents are a characteristic of this sub-order, and contrast with myomorphs like the mouse and rat. Many hystricomorphs show structural and functional modifications of the ovary in the form of accessory corpora lutea, which enhance progesterone secretion for the maintenance of pregnancy during the long gestational periods (Tam, 1974). This additional luteal tissue arises from luteinization of unovulated follicles, and has been observed in the chinchilla, the Canadian porcupine, Erethizon dorsatum, and the mountain viscacha, Lagidium peruanum (Weir \& Rowlands, 1974). In the African mole-rats (F. Bathyergidae), accessory corpora lutea have been reported in the ovaries of both reproductive and non-reproductive females of the common mole-rat (Cryptomys h. hottentotus) and Damaraland mole-rat (Cryptomys damarensis) which are social species (Bennett, 1988, 1989). The ovaries of the Cape mole-rat (Georychus capensis), which lives solitarily, also contain accessory corpora lutea outside the breeding season (Bennett, 1988). The physiological significance of these structures in non-reproductive animals is not known, and they also occur in non-pregnant naked mole-rat queens, but not in non-breeding females (C. G. Faulkes, unpublished results).

Although fertility is normally completely inhibited in non-breeding female naked mole-rats whilst they remain in their colony, results from this study show that, if the social environment is manipulated, in this case by separating females from their parent colonies, then ovarian cyclicity may start in as little as 7 days. Pregnancy can also occur rapidly in previously non-breeding individuals, as shown by 3 of the females separated which underwent one cycle after being paired with a male, then at the following period of oestrus became pregnant (e.g. Females 4 and 29, Fig. 2). The observation that 4 out of the 5 singly housed females underwent what appeared to be normal cycles, together with the fact that breeding queens always solicit mating behaviour (Jarvis, 1990a), suggests that the naked mole-rat may be a spontaneous ovulator. Among other hystricomorphs, both the guinea-pig and the chinchilla are known to be spontaneous ovulators (Weir \& Rowlands, 1974).

The rapid onset of reproduction in non-breeding female naked mole-rats is remarkable given the complete suppression imposed on them in their colonies, which apparently continues for their entire lifespan (Jarvis, 1990b). Naked mole-rat colonies have been kept in excess of 15 years in captivity (Jarvis, 1990b), yet some still retain the original breeding queen. Therefore, although most mole-rats may never breed, it is important that new breeding females can be recruited quickly if required, for example if the queen dies, or if a group is separated from the parent colony. In the latter case, fast recruitment of young may be crucial to the survival of the colony, because below a certain group size the energy expended in digging and foraging will exceed the resources that a small group can exploit (Brett, 1986). By adopting this system of reproduction and a behavioural division of labour, the naked mole-rat is able to exploit an ecological niche in a harsh environment where rainfall is low and unpredictable. By having indivduals dedicated to maintaining the burrow system and foraging for the rich but scattered food sources, the queen is left free to breed continuously (Jarvis, 1981, 1985). 
Density-dependent suppression of reproduction mediated by urinary primer pheromones is commonly observed in many species of rodents. This phenomenon is thought to play a role in regulating natural rodent populations by controlling the rate of sexual maturation (Vandenbergh \& Coppola, 1986). The naked mole-rat does not appear to fit into this category because, irrespective of the number of animals in the colony, the size of the burrow system and the available food, reproducton is restricted to one female (Brett, 1986; Jarvis, 1978, 1981, 1985). The naked mole-rat is more similar to examples of socially-induced female infertility which result from the presence of a dominance hierarchy, found in several mammalian species outside the order Rodentia, e.g. dwarf mongoose, Helogale parvula (Rood, 1980), silver-backed jackal, Canis mesomelas (Moehlman, 1983), talapoin monkeys, Miopithecus talapoin (Abbott et al., 1986), cotton-top tamarins (French et al., 1984), and the common marmoset monkey (Abbott, 1988). These situations arise when dominant breeding females require non-reproductive subordinate 'helpers' to assist with the rearing of offspring and protection against predators, thereby maximizing their chances of survival (Wasser \& Barash, 1983).

We thank the Office of the President and the Ministry of Tourism and Wildlife, Republic of Kenya, for permission to carry out the field work; Nathan and Leonard Mthuku and Mr S. H. Faulkes for invaluable help with animal capture; to $\mathrm{Mr} \mathrm{M}$. Kyunuve for allowing trapping on his land; Dr J. Else (National Museums of Kenya) and Dr R. M. Eley (Institute of Primate Research, Nairobi) for advice and assistance with the field work; Mr J. Shasha for collecting urine samples in Cape Town; Mr M. J. Llovet and the laboratory animal staff at the Institute of Zoology, London, for care and maintenance of the animals; the N.I.D.D.K., Baltimore, USA, and the National Hormone and Pituitary Program at the University of Maryland School of Medicine, USA, for the rat LH reference preparation (RLH-1-7); Professor A. P. F. Flint for criticism of the manuscript; and $\mathrm{Mr}$ T. Dennett and Miss M. J. Walton for preparation of the figures. This work was supported by an MRC/AFRC Programme Grant, travel grants from The Royal Society, The Wellcome Trust, The Society for Endocrinology, Journal of Reproduction and Fertility Ltd and the Institute of Zoology to D.H.A.; an SERC Research Studentship, and travel grants from the SERC and Journal of Reproduction and Fertility Ltd to C.G.F., and grants from C.S.I.R., the University of Cape Town and the National Geographic Society to J.U.M.J.

\section{References}

Abbott, D.H. (1987) Behaviourally mediated suppression of reproduction in female primates. $J$. Zool, Lond. 213, $455-470$.

Abbott, D.H. (1988) Natural suppression of fertility. Symp. zool. Soc. Lond. 60, 7-28.

Abbott, D.H., Keverne, E.B., Moore, G.F. \& Yodyingyuad, U. (1986) Social suppression of reproduction in subordinate talapoin monkeys, Miopithecus talapoin. In Primate Ontogeny, Cognition and Social Behaviour, pp. 329-341. Eds J. Else \& P. Lee. Cambridge University Press, Cambridge.

Abbott, D.H., Hodges, J.K. \& George, L.M. (1988) Social status controls LH secretion and ovulation in female marmoset monkeys (Callithrix jacchus). J. Endocr. 117, 329-339.

Bennett, N.C. (1988) The trend towards sociality in three species of Southern African mole-rats. Ph.D. thesis, University of Cape Town.

Bennett, N.C. (1989) The social structure and reproductive biology of the common mole-rat Cryptomys $h$. hottentotus and remarks on the trends in reproduction and sociality in the family Bathyergidae. $J$. Zool., Lond. 219, 45-59.
Bonney, R.C., Wood, D.J. \& Kleiman, D.G. (1982) Endocrine correlates of behavioural oestrus in the female giant panda (Ailuropoda melanoleuca) and associated hormonal changes in the male. J. Reprod. Fert. 64, 209-215.

Breed, W.G. (1976) Effect of environment on ovarian activity of wild hopping mice (Notomys alexis). $J$. Reprod Fert. 47, 395-397.

Brett, R.A. (1985) Captive breeding and management of naked mole rats (Heterocephalus glaber). Proc. Symp. Assoc. Br. Wild Animal Keepers. 10, 6-11.

Brett, R.A. (1986) Ecology and behaviour of the naked mole-rat Heterocephalus glaber (Ruppell) Rodentia: Bathyergidae. Ph.D. thesis, University of London.

Brown, R.E. \& MacDonald, D.W. (1984) Mammalian Social Odours. Oxford University Press, Oxford.

Faulkes, C.G., Abbott, D.H. \& Jarvis, J.U.M. (1989) Reproductive suppression in female naked mole-rats, Heterocephalus glaber. In Comparative Reproduction In Mammals and Man, pp. 155-161. Ed. R. M. Eley. Institute of Primate Research/National Museums of Kenya, Nairobi. 
Faulkes, C.G., Abbott, D.H., Liddell, C.E., George, L.M. \& Jarvis, J.U.M. (1990a) Hormonal and behavioural aspects of reproductive suppression in female naked mole-rats Heterocephalus glaber. In The Biology of The Naked Mole-Rat. Eds P. W. Sherman, J. U. M. Jarvis \& R. Alexander. Princeton University Press, New York.

Faulkes, C.G., Abbott, D.H. \& Mellor, A.L. (1990b) Investigation of genetic diversity in wild colonies of naked mole-rats by genetic fingerprinting. J. Zool., Lond.

French, J.A., Abbott, D.H. \& Snowdon, C.S. (1984) The effect of social environment on oestrogen excretion, scent marking and sociosexual behaviour in tamarins (Saguinus oedipus). Am. J. Primatol. 6, 155-167.

Haigh, G.R. Cushing, B.S. \& Bronson, F.H. (1988) A novel postcopulatory block of reproduction in whitefooted mice. Biol. Reprod. 38, 623-626.

Harlow, C.R., Gems, S., Hodges, J.K \& Hearn, J.P. (1984) The relationship between plasma progesterone and the timing of ovulation and early embryonic development in the marmoset monkey (Callithrix jacchus). J. Zool., Lond. 201, 272-282.

Hodges, J.K. (1986) Monitoring changes in reproductive status. Int. Zoo $Y b .24 / 25,126-130$.

Hodges, J.K., Gulick, B.A. Czekala, N.M. \& Lasley, B.L. (1981) Comparison of urinary oestrogen excretion in South American primates. J. Reprod. Fert. 61, 83-90.

Hodges, J.K., Eastman, S.A.K. \& Jenkins, N. (1983) Sex steroids and their relationship to binding proteins in the serum of the marmoset monkey (Callithrix jacchus). J. Endocr. 96, 443-450.

Hodges, J.K., Cottingham, P., Summers, P.M. \& Yingnan, L. (1987) Controlled ovulation in the marmoset monkey (Callithrix jacchus) with human chorionic gonadotrophin following prostaglandin induced luteal regression. Fert. Steril. 48, 299-305.

Jarvis, J.U.M. (1978) Energetics of survival in Heterocephalus glaber (Ruppell), the naked mole-rat (Rodentia: Bathyergidae). Bull. Carn. Mus. Nat. Hist. No. 6, 81-87.

Jarvis, J.U.M. (1981) Eu-sociality in a mammalcooperative breeding in naked mole-rat Heterocephalus glaber colonies. Science, NY 212, 571-573.

Jarvis, J.U.M. (1985) Ecological studies on Heterocephalus glaber, the naked mole-rat, in Kenya. Nat. Geographic Sci. Rep. 20, 429-437.

Jarvis, J.U.M. (1990a) Reproduction. In Biology of The Naked Mole-Rat. Eds P. W. Sherman, J. U. M. Jarvis \& R. Alexander. Princeton University Press, New York.

Jarvis, J.U.M. (1990b) Capture methods, maintenance in captivity and transport. In The Biology Of The Naked Mole-Rat. Eds P. W. Sherman, J. U. M. Jarvis \& R. Alexander. Princeton University Press, New York.

Jarvis, J.U.M., O'Riain, J. \& McDaid, E. (1990) Growth and factors affecting body size in Heterocephalus glaber. In The Biology Of The Naked Mole-Rat. Eds
P. W. Sherman, J. U. M. Jarvis \& R. Alexander, Princeton University Press, New York.

Kaplan, J.R., Adams, M.R., Koritnik, D.R., Rose, J.C. \& Manuk, S.B. (1986) Adrenal responsiveness and social status in intact and ovariectomized Macaca fascicularis. Am. J. Primatol. 11, 181-193.

Kirkland, L.E. \& Bradley, E.L. (1986) Reproductive inhibition and serum prolactin levels in laboratory populations of the prairie deermouse. Biol. Reprod. $35,579-586$

Lacey, E.A. \& Sherman P.W. (1990) Social organization of naked mole-rat (Heterocephalus glaber) colonies: evidence for a division of labour. In The Biology of The Naked Mole-Rat. Eds J. U. M. Jarvis, P. W. Sherman \& R. Alexander. Princeton Press University, New York

Lasley, B.L. (1985) Methods for evaluating reproductive function in exotic species. Adv. vet. Sci. comp. Med. 30, 209-228.

Massey, A. \& Vandenbergh, J.G. (1980) Puberty delay by a urinary cue from female house mice in feral populations. Science, $N Y$ 209, 821-822.

McClintock, M.K. (1983) Pheromonal regulation of the ovarian cycle: enhancement, suppression and synchrony. In Pheromones And Reproduction In Mammals, pp. 113-149. Ed. J. G. Vandenbergh. Academic Press, New York.

Moehlman, P.D. (1983) Socioecology of silverbacked and golden jackals (Canis mesomelas and Canis aureus). Spec. Publ. Amer. Soc. Mamm. 7, 423-453.

Rood, J.P. (1980) Mating relationships and breeding suppression in the dwarf mongoose. Anim. Behav. 28, $143-150$.

Tam, W.H. (1974) The synthesis of progesterone in some hystricomorph rodents. Symp. zool. Soc. Lond. 34, 363-384.

Van Damme, M.-P., Robertson, D.M. \& Diczfalusy, E. (1974) An improved in vitro bioassay method for measuring luteinizing hormone (LH) activity using mouse Leydig cell preparations. Acta endocr., Copenh. $77,655-671$.

Vandenbergh, V.G. \& Coppola, D.M. (1986) The physiology and ecology of puberty modulation by primer pheromones. Adv. Stud. Behav. 16, 71-107.

van der Lee, S. \& Boot, L.M. (1955) Spontaneous pseudopregnancy in mice. Acta physiol. pharmacol. neerl. 4, 442-443.

Wasser, S.K. \& Barash, D.P. (1983) Reproductive suppression among female mammals: implications for biomedicine and sexual selection theory. Q. Rev. Biol. 58, 513-538.

Weir, B.J. \& Rowlands, I.W. (1974) Functional anatomy of the hystricomorph ovary. Symp. zool. Soc. Lond. 34, 303-332.

Received 22 June 1989 